\title{
Electromagnetically Compatible and Virtual Flux DPC Control Techniques for 3-Phase Distributed Generation Fed by Active Rectifier
}

\author{
Bhuthukuri Rajesh Khanna, Poonam Upadhyay, Munagala Surya Kalavathi
}

\begin{abstract}
This paper gives different control mechanisms comparison for active rectifiers fed grid connected 3-phase distributed generation systems from non-conventional energy sources. The control strategies presented here are Direct Power Control, 2 other DPC methods DPC to reduce CM voltage emissions that are EMC-I-DPC and EMC-II-DPC. Another two strategies are also presented with a concept of virtual flux i.e EMC-I-VF-DPC and EMC-II-VF-DPC. MATLAB/Simulink software is used to implement the so called techniques and the parameters like are injected current into electric grid, \%Total harmonic distortion of current injected vs. generated power, \%Total harmonic distortion of current injected vs DC link voltage (Vdc) and \%Total harmonic distortion of current injected vs CM voltages are shown.
\end{abstract}

Keywords: Voltage Oriented Control, Field oriented control Direct Torque Control, Electric grid, Direct Power Control, Common mode emissions, Active Rectifiers, Electro-Magnetically Compatible, Virtual Motor, Distributed Generation, Virtual flux, Reference Frame theory

\section{INTRODUCTION}

In the recent years there is a continuous development of control strategies for grid connected active rectifiers [1]. The reason for the use is of the severe harmonic pollution caused by the commonly used line-side diode rectifiers in power systems. It is interesting to note that, active or passive filters are used for active rectifiers gives the alternate solution. The most commonly used techniques for grid connected rectifiers are based on current control of VSI's [2]. Out of these, the famous and usually adopted technique is purely on the idea of controlling the active \& reactive powers directly by selecting proper switching state patterns on the basis grid voltage space-vector instantaneous position [3]. This one is called as Direct Power Control technique. DPC is further improvised with virtual flux version, named VF-DPC [4] which is based on the equivalence between electrical machine and an electrical grid [5]. A detailed analysis and comparison made between theoretical and experimental (MATLAB/Simulink) of aforementioned strategies obtained in [6], with a complete focus of controlled load behavior with respect to an adjustable speed electric drive.

Revised Manuscript Received on February 05, 2020.

* Correspondence Author

Bhuthukuri Rajesh Khanna, Department of EEE, JNTUHCEH JNT University Hyderabad, India. E-mail: rajeshkhanna202@gmail.com

Dr. Poonam Upadhyay, Department of EEE, VNRVJIET Hyderabad, India. E-mail: upadhyay_p@vnrvgiet.in

Dr. Munagala Surya Kalavathi, Department of EEE, JNTUHCEH JNT University Hyderabad, India. e-mail: munagala12@yahoo.co.in

(C) The Authors. Published by Blue Eyes Intelligence Engineering and Sciences Publication (BEIESP). This is an open access article under the CC BY-NC-ND license (http://creativecommons.org/licenses/by-nc-nd/4.0/)
Here control methods derived for active rectifiers can be properly used because of their bi-directional power flow advantage. Initially classic DPC in generating mode is done and next to this the new technique referred as EMC-DPC has been derived for 3-phase distributed generation fed by non-conventional energy sources [7] [8]. In this new technique the CM voltages produced by VSCs towards grid are reduced. This is done without using a null and vector and with the proper selection of either even or odd vectors where the grid voltage lies. This leads to a small increment of the harmonic content of the injected current waveform w.r.t DPC classic technique.

Here in this paper the full attention is towards the control techniques behavior in generating mode. At the same time comparative analysis extended to the virtual flux versions named VF-DPC, and to the EMC-I-DPC and EMC-II-DPC. At last we shown how percentage Total Harmonic Distortion of the injected currents effected by taking the ratio of DC link voltage and grid voltage amplitude into consideration. The result analysis compared purely from the point of injected currents into the grid's harmonic content, current injected Total Harmonic Distortion vs. Power generated and vs. voltage (DC Link) Vdc.

\section{DTC AND DPC}

Direct Torque Control or named Voltage Oriented Control used for control of adjustable speed drives is the basis for deriving Direct Power control strategy. From the point of drive control, the main idea in the DPC are finding switching patterns instantaneously for VSI permitting to increase or decrease directly, without any current control. This is done in a decoupled way with this there is exchange of power (active and reactive) between the DC stage and grid. In the advanced version named VFDPC power (active and reactive) are estimated not on the basis of voltage but on the components of virtual flux so there is a further improvement of technique developed for the drives. Extensive comparative analysis made between DPC and all versions of VFDPC done in [5] [6] from the view point of Power (active \& reactive) power ripples and harmonic content of currents injected.

This paper addressed the behavior of generator only because especially with DPC case, the nature of control systems as a controlled load or a generation system is not perfectly symmetric. The powers assumed negative generated by non-conventional energy sources and positive when it is absorbed by the DC source from the grid in both control systems modeling of all the control systems presented.

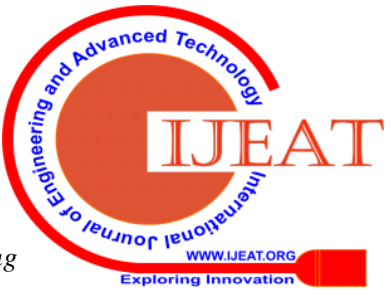




\section{A. Direct Power Control}

The power (Reactive \& Active) in a decoupled way exchanged between the inverter and the grid, leaving the current control is the main source of idea of DPC. The optimum choosing of VSI switching pattern is based on the demand of active \& reactive power and instantaneous position of the grid voltage space-vector. Table I shows, If ug (grid voltage vector) lies in sector ' $k$ ' instantaneously then the effect $\mathrm{P}$ and $\mathrm{Q}$, exchanged with the grid caused by the application of any voltage vector of VSI can be analyzed, which considered sub-sector inside a sector (A is the first and $\mathrm{B}$ the second sub-sector in the rotating sense of the grid voltage vector [5]). The big and small variation is shown by double and single arrows in the table.

Table. I: Reactive and Active powers influenced by VSC voltage vectors

\begin{tabular}{|l|l|l|l|l|l|l|l|}
\hline & $\mathbf{u}_{\mathbf{0}}$ & $\mathbf{u}_{\mathbf{k}}$ & $\mathbf{u}_{\mathbf{k}+\mathbf{1}}$ & $\mathbf{u}_{\mathbf{k}+2}$ & $\mathbf{u}_{\mathbf{k}+3}$ & $\mathbf{u}_{\mathbf{k}-\mathbf{1}}$ & $\mathbf{u}_{\mathbf{k}-\mathbf{2}}$ \\
\hline $\mathbf{P}$ & $\uparrow \uparrow$ & $\downarrow \downarrow$ & $\uparrow \uparrow$ & $\uparrow \uparrow$ & $\uparrow \uparrow$ & $\uparrow$ & $\uparrow \uparrow$ \\
\hline $\mathbf{Q}$ & $\uparrow \mathrm{A} \downarrow \mathrm{B}$ & $\uparrow \mathrm{A} \downarrow \mathrm{B}$ & $\uparrow \uparrow$ & $\uparrow$ & $\downarrow \mathrm{A} \uparrow \mathrm{B}$ & $\downarrow \downarrow$ & $\downarrow$ \\
\hline
\end{tabular}

Further for the experimental application of the procedure, optimized VSI switching patterns are shown in Table II, with the usage of Table I.

Table. II: optimized switching patterns

\begin{tabular}{|l|l|l|l|}
\hline $\begin{array}{l}\text { Active } \\
\text { Power }\end{array}$ & $\begin{array}{l}\text { Reactive } \\
\text { Power }\end{array}$ & $\begin{array}{l}\text { Sub- } \\
\text { Sector } \\
\text { 'A' }\end{array}$ & $\begin{array}{l}\text { Sub- } \\
\text { Sector } \\
\text { 'B' }\end{array}$ \\
\hline \multirow{2}{*}{$\mathrm{P} \uparrow$} & $\mathrm{Q} \uparrow$ & $\mathrm{U}_{0}$ & $\mathrm{u}_{0}$ \\
\cline { 2 - 4 } & $\mathrm{Q} \downarrow$ & $\mathrm{u}_{\mathrm{k}-1}$ & $\mathrm{u}_{0}$ \\
\hline \multirow{2}{*}{$\mathrm{P} \downarrow$} & $\mathrm{Q} \uparrow$ & $\mathrm{u}_{\mathrm{k}}$ & $\mathrm{u}_{\mathrm{k}+1}$ \\
\cline { 2 - 4 } & $\mathrm{Q} \downarrow$ & $\mathrm{u}_{\mathrm{k}-1}$ & $\mathrm{u}_{\mathrm{k}}$ \\
\hline
\end{tabular}

The below mentioned mathematical equations shows the power (active \& reactive) for control feedback has been estimated instantaneously.

$$
\begin{aligned}
& P=u_{s A} i_{s A}+u_{s B} i_{s B}+u_{s C} i_{s C} \\
& Q=\frac{1}{\sqrt{3}}\left(\left(u_{s B}-u_{s C}\right) i_{s A}\right. \\
& +\left(u_{s C}-u_{s A}\right) i_{s B} \\
& \left.+\left(u_{s A}-u_{s B}\right) i_{s C}\right)
\end{aligned}
$$

As in the Voltage Oriented Control (VOC), no coordinate variation is required for the calculation of Power (active \& reactive) based on 3-phase VSI currents and voltages. Hysteresis controllers (2-level) are used to control Power (active \& reactive). An algorithm of sector and sub- sector finding permits the instantaneous lying of voltage vector of grid estimation is done with a assumption of 300. A sampling frequency $15 \mathrm{kHz}$ is taken in the implementation of DPC and the scheme is depicted in Fig. 2.

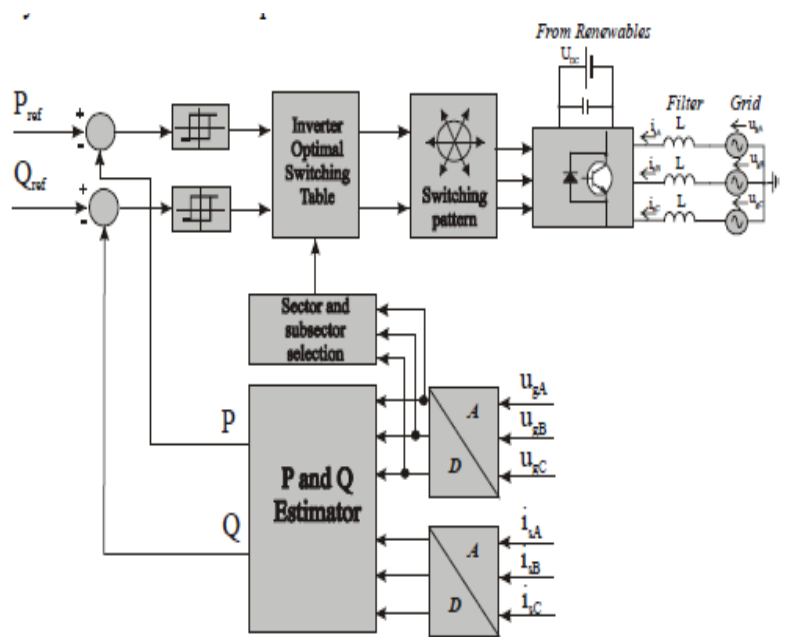

Fig.2: Direct Power Control Schemes Block Diagram

\section{B. Electromagnetically Compatible-I-DPC}

No CM voltage variation is generated if only even or only odd voltage vectors (active) are used (uk, with $\mathrm{k}$ odd or even) but a CM voltage variation of UDC/3 magnitude is generated if a transition from even voltage to odd voltage vector (or vice versa) occurs, variation of UDC/3 magnitude is generated if a transition from odd (even) voltage vector to ' 0 th' ( 7 th) voltage vector occurs and variation of magnitude 2UDC/3 is generated if a transition from odd (even) voltage vector to the 7th (0th) voltage vector occurs. So in the view of emissions of CM, the worst case is a transition from an odd (even) voltage vector to the 7th (0th) voltage vector.The CM voltage amplitudes with different cases for each inverter state are presented in Table III.

Table. III: State of the VSI \& CM emissions

\begin{tabular}{|c|c|c|c|c|}
\hline State & $\mathrm{U}_{\mathrm{SA} 0}$ & $\mathrm{U}_{\mathrm{SB} 0}$ & $\mathrm{U}_{\mathrm{SC} 0}$ & $\mathrm{U}_{\mathrm{com}}$ \\
\hline $\mathrm{u}_{0}(0,0,0)$ & $-\mathrm{U}_{\mathrm{DC}} / 2$ & $-\mathrm{U}_{\mathrm{DC}} / 2$ & $-\mathrm{U}_{\mathrm{DC}} / 2$ & $-\mathrm{U}_{\mathrm{DC}} / 2$ \\
\hline $\mathrm{u}_{1}(1,0,0)$ & $\mathrm{U}_{\mathrm{DC}} / 2$ & $-\mathrm{U}_{\mathrm{DC}} / 2$ & $-\mathrm{U}_{\mathrm{DC}} / 2$ & $-\mathrm{U}_{\mathrm{DC}} / 6$ \\
\hline $\mathrm{u}_{2}(1,1,0)$ & $\mathrm{U}_{\mathrm{DC}} / 2$ & $\mathrm{U}_{\mathrm{DC}} / 2$ & $-\mathrm{U}_{\mathrm{DC}} / 2$ & $\mathrm{U}_{\mathrm{DC}} / 6$ \\
\hline $\mathrm{u}_{3}(0,1,0)$ & $-\mathrm{U}_{\mathrm{DC}} / 2$ & $\mathrm{U}_{\mathrm{DC}} / 2$ & $-\mathrm{U}_{\mathrm{DC}} / 2$ & $-\mathrm{U}_{\mathrm{DC}} / 6$ \\
\hline $\mathrm{u}_{4}(0,1,1)$ & $-\mathrm{U}_{\mathrm{DC}} / 2$ & $\mathrm{U}_{\mathrm{DC}} / 2$ & $\mathrm{U}_{\mathrm{DC}} / 2$ & $\mathrm{U}_{\mathrm{DC}} / 6$ \\
\hline $\mathrm{u}_{5}(0,0,1)$ & $-\mathrm{U}_{\mathrm{DC}} / 2$ & $-\mathrm{U}_{\mathrm{DC}} / 2$ & $\mathrm{U}_{\mathrm{DC}} / 2$ & $-\mathrm{U}_{\mathrm{DC}} / 6$ \\
\hline $\mathrm{u}_{6}(1,0,1)$ & $\mathrm{U}_{\mathrm{DC}} / 2$ & $-\mathrm{U}_{\mathrm{DC}} / 2$ & $\mathrm{U}_{\mathrm{DC}} / 2$ & $\mathrm{U}_{\mathrm{DC}} / 6$ \\
\hline $\mathrm{u}_{7}(1,1,1)$ & $\mathrm{U}_{\mathrm{DC}} / 2$ & $\mathrm{U}_{\mathrm{DC}} / 2$ & $\mathrm{U}_{\mathrm{DC}} / 2$ & $\mathrm{U}_{\mathrm{DC}} / 2$ \\
\hline
\end{tabular}

Because of this, simply we can avoid null voltage vectors (0th \& 7th) to reduce the drive CM emissions generated whatever inverter control strategy is implemented. This assumption is very much helpful from the control point of view if a DPC is used. The fact here it is in the actual DPC [3] the 0th voltage vector is taken when active power increase is required, and reactive power increase \& decrease required (see Table. IV).

The application of the kth voltage vector produces a drastic decrease of absorbed P \& a small increment (sub-sector A) or decrement of (sub-sector B) of the $\mathrm{Q}$ is taken place when voltage vector grid lies in the kth sector. At the same time the application of the $\mathrm{uk}+2$ voltage vector produces a small increase in both $\mathrm{P} \& \mathrm{Q}$ while uk-2 the voltage vector produces a small increase in $\mathrm{P} \&$ decrease in $\mathrm{Q}$. 


\section{Electromagnetically Compatible-II-DPC}

The shortfalls and disadvantages of EMC-I-DPC overcome in proposed EMC-II-DPC. The main idea behind the proposed EMC-II-DPC is employing EMC-I-DPC as far as $\mathrm{Q}$ error is enough bounded and whenever high $\mathrm{Q}$ variations are needed we use $\mathbf{u}_{\mathbf{k}} \pm \mathbf{1}$ voltage vector. If we use 2-level hysteresis controller it is not possible so we have to adopt 4level hysteresis controller (Fig. 3) for reactive power control.

4-level controller provides output of \pm 1 (When error of $\mathrm{Q}$ is low), $\mathbf{u k} \pm \mathbf{2}$ vectors come in to picture (EMC-I-DPC) and provides output \pm 2 ( when error of $\mathrm{Q}$ is high) and thus the vectors uk+- 1 are used.

Table.V. shows the summary of proposed Electromagnetically-II-DPC

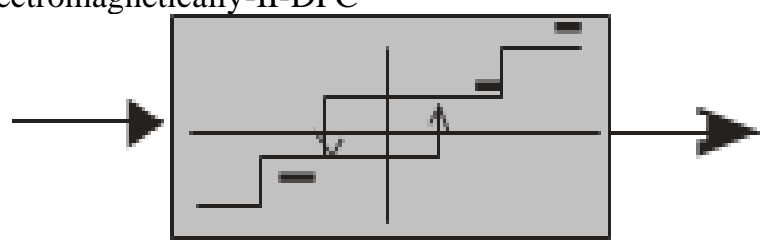

Fig.3: Hysteresis Controller (4-level)

Table. IV: Electromagnetically-I-DPC Optimal Switching pattern

\begin{tabular}{|l|l|l|}
\hline Active Power & Reactive Power & $\begin{array}{l}\text { Sector } \\
\mathrm{k}\end{array}$ \\
\hline \multirow{2}{*}{$\mathrm{P} \uparrow$} & $\mathrm{Q} \uparrow$ & $\mathrm{u}_{\mathrm{k}+2}$ \\
\cline { 2 - 3 } & $\mathrm{Q} \downarrow$ & $\mathrm{u}_{\mathrm{k}-2}$ \\
\hline \multirow{2}{*}{$\mathrm{P} \downarrow$} & $\mathrm{Q} \uparrow$ & $\mathrm{u}_{\mathrm{k}}$ \\
\cline { 2 - 3 } & $\mathrm{Q} \downarrow$ & $\mathrm{u}_{\mathrm{k}}$ \\
\hline
\end{tabular}

The control method concluded in Table IV called proposed Electromagnetically-I-DPC based on the above considerations.

The other important point noticed w.r.t CM emissions is that at each sector crossing, variation of $\mathrm{CM}$ is minimum and equal to UDC/6 magnitude. Because of this in each period of the grid (f), only 6 variations of CM equal to UDC/6 magnitude appear in steady-state theoretically. But the benefits obtained from reduction of CM emissions of VSC are outweighed by higher ripples both in $\mathrm{P} \& \mathrm{Q}$ waveforms and currents injected into grid have higher harmonic contents.

The above mentioned electromagnetically -I direct power control can be used in a straightforward manner with simple use of electrical software's since at every sampling time a proper space voltage vector is created

Table. V: Electromagnetically-II-DPC Optimal Switching pattern

\begin{tabular}{|l|l|l|}
\hline Active Power & Reactive Power & $\begin{array}{l}\text { Sector } \\
\mathrm{k}\end{array}$ \\
\hline \multirow{2}{*}{$\mathrm{P} \downarrow$} & $\mathrm{Q} \uparrow$ & $\mathrm{u}_{\mathrm{k}}$ \\
\cline { 2 - 3 } & $\mathrm{Q} \downarrow$ & $\mathrm{u}_{\mathrm{k}}$ \\
\hline \multirow{2}{*}{$\mathrm{P} \uparrow$} & $\mathrm{Q} \uparrow \uparrow$ & $\mathrm{u}_{\mathrm{k}+1}$ \\
\cline { 2 - 3 } & $\mathrm{Q} \downarrow \downarrow$ & $\mathrm{u}_{\mathrm{k}-1}$ \\
\hline \multirow{2}{*}{$\mathrm{P} \uparrow$} & $\mathrm{Q} \uparrow$ & $\mathrm{u}_{\mathrm{k}+2}$ \\
\cline { 2 - 3 } & $\mathrm{Q} \downarrow$ & $\mathrm{u}_{\mathrm{k}-2}$ \\
\hline
\end{tabular}

With the application of new proposed EMC-II-DPC the drawbacks of EMC-I-DPC has been reduced effectively with the result there is a good control over reactive power error and it has been reduced to zero also means there is no such Q exchanged with the electric grid like in EMC-IDPC. Same time we observe lower ripple content in the waveforms of power (Active \& Reactive) and currents injected into the electric grid harmonic contents are further reduced. Another worth important point to note that the waveform of CM emissions is is same like EMC-I-DPC i.e 6-step with small additional spikes because of the often usage of vectors uk \pm 1 . It is interesting to observe that the content harmonic of $\mathrm{CM}$ emissions at same $\mathrm{kHz}$ sampling frequencies slightly increases w.r.t EMC-I-DPC but this is very much lower compared to original DPC so this deterioration can be neglected.

\section{Virtual Flux}

To use the controlling methods of electric motors effectively the concept of "Virtual Flux" and "Virtual Motor" is frequently used in the VSC fed distributed generation. Electric grid and virtual electric motor are taken the same, with this equivalence the electric grid is replaced by virtual motor having transient $\mathrm{X}_{\mathrm{L}}$ (motor) equivalent to the connecting filter $\mathrm{X}_{\mathrm{F}}$ of the inverter (active rectifier) and $\mathrm{E}_{\mathrm{b}}$ of (motor) equivalent to the grid voltages (active rectifier).

Based on the "Virtual Motor" imagination a flux called "Virtual flux" is defined as time integral of electric grid voltages (phase shifted by “ $\pi / 2$ " radians w.r.t grid voltages) which is an equivalent to magnetic flux of electric motor.

The following equations represent the virtual flux $d \& q$ axes components of virtual flux in the stationary reference frame:

$$
\begin{aligned}
& \psi_{g D}=\int\left(u_{s D}+L \frac{d i_{s D}}{d t}\right) d t \\
& \psi_{g Q}=\int\left(u_{s Q}+L \frac{d i_{s Q}}{d t}\right) d t
\end{aligned}
$$

In the VF-DPC a flux called "Virtual flux" used to calculate $\mathrm{P} \& \mathrm{Q}$ instead of electric grid voltage which is noisy.

The mathematical equations given below shows the usage "Virtual flux" in calculation of P \& Q:

$$
P=\frac{3}{2} \omega\left(\psi_{g D} i_{s Q}-\psi_{d Q} i_{s D}\right)
$$

I.

$$
Q=\frac{3}{2} \omega\left(\psi_{g D} i_{s D}+\psi_{g Q} i_{s Q}\right)
$$



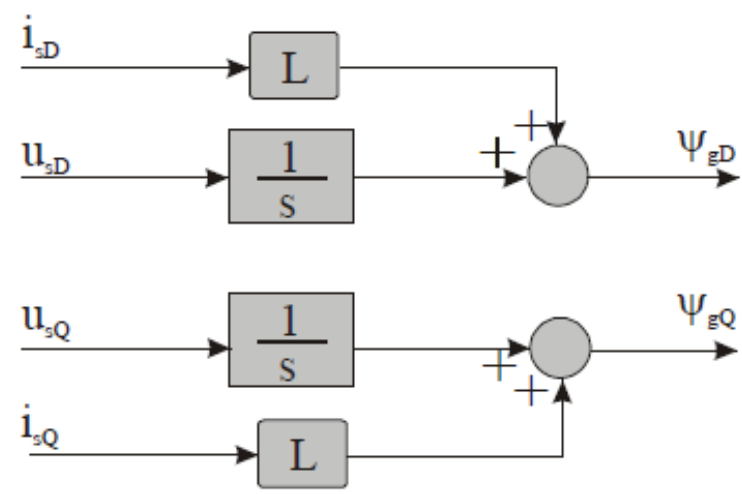

Fig.4: VLFE (Estimator for Virtual Flux) Block Diagram

Application of "Virtual flux" concept shows that there is a considerable reduction in the harmonics of grid current and ripple content of $\mathrm{P} \& \mathrm{Q}$.

Approximation of pure integrator with FOLPF known as "Open loop integration" is required to estimate the "Virtual Flux" for experimental applications.

\section{DISCUSSIONS AND RESULTS}

The control strategies discussed Direct Power Control, Electromagnetically Compatible-I-Direct Power Control, Electromagnetically Compatible-II-Direct Power Control Virtual Flux- Direct Power Control are implemented in MATLAB/Simulink. All techniques are implemented in discrete frequency domain with a sampling frequency of 15 $\mathrm{kHz}$.

Figure.5 shows inverter current vs. time waveforms of DPC \& VF-DPC and their FFT analysis with same working conditions under steady-state. VF-DPC has better injected

DPC
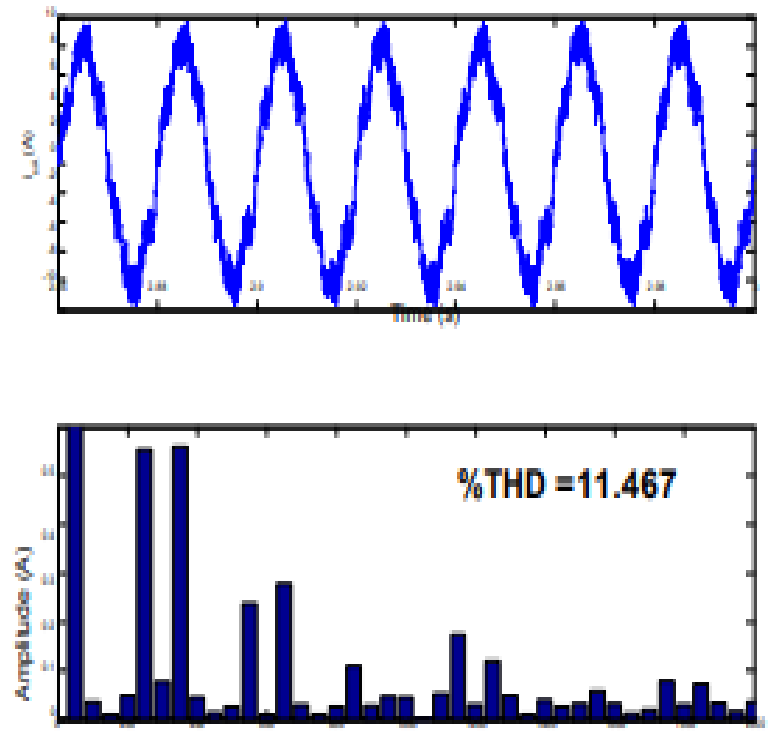

Frequency $\left(\mathrm{H}_{2}\right)$ current harmonic content when compared to Classical DPC w.r.t \% THD and h-by-h analysis.

Figure.6 shows inverter current vs. time waveforms of EMC-I-DPC \& EMC-I-VF-DPC and their FFT analysis with same working conditions under steady-state. EMC-I-VFDPC has little good injected current harmonic content when compared to EMC-I-DPC w.r.t \% THD and h-by-h analysis. By the conclusion, Figure.7 shows inverter current vs. time waveforms of EMC-II-DPC \& EMC-II-VF-DPC and their FFT analysis with same working conditions under steadystate. EMC-II-VF-DPC has slightly better injected current harmonic content when compared to EMC-II-DPC w.r.t \% THD and h-by-h analysis.

The CM emissions generated by the VSI with EMC-I-DPC \& EMC-II-DPC, and their FFT analysis presented in Figure.8. The figure shows the CM emissions of VSC is a square waveform with fundamental (f) at $150 \mathrm{~Hz}$ and harmonics occurred only at low (f), decreasing inversely with frequency increase with EMC-I-DPC but EMC-II-DPC is same as EMC-I-DPC with some additional internal spikes so if we observe the FFT of EMC-II-DPC it has lower values of (f) compared to EMC-I-DPC.

The injected current \%THD vs. power generated is shown in Figure.9 and Fig. 10 shows EMC-I-DPC \& EMC-II-DPC \%THD injected current vs Vdc.

The figure 10 reveals that there is a considerable increment in the THD for decreasing values of DC link voltage.

With this we can finally conclude that the Direct Power control algorithms for active rectifier fed distributed generation does not present any considerable variation in the total harmonic distortion (THD) for the different values of DC link voltage.

The injected current \%THD vs. power generated is drawn as a final comparison.
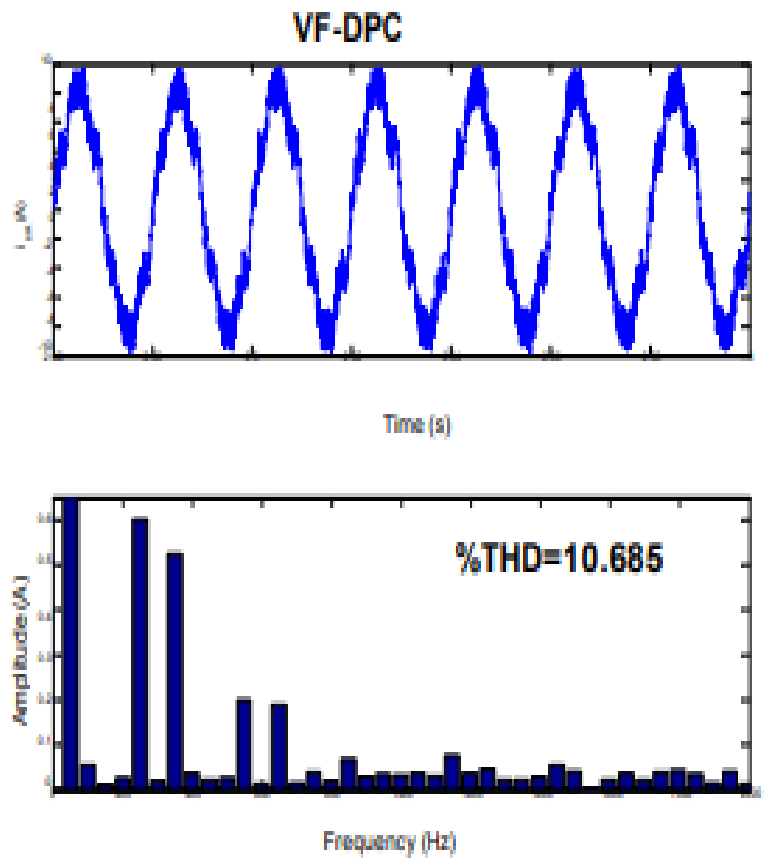

Fig. 5: Injected Inverter current and its spectra with a) DPC and b) VF-DPC at Pref $=-2 \mathrm{~kW}$, Qref=0VAR

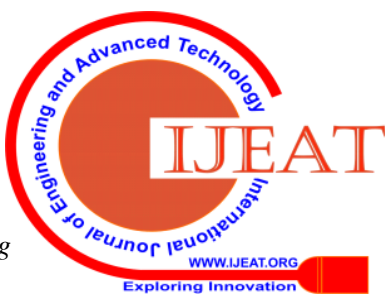



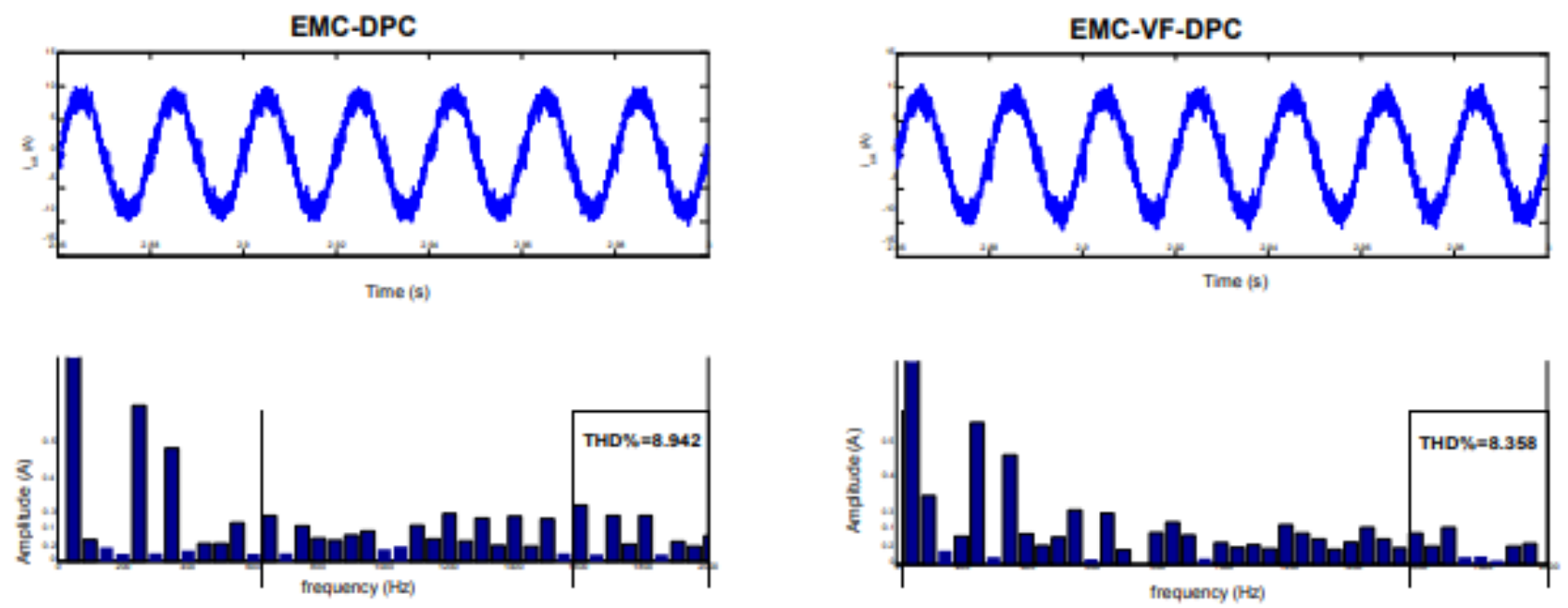

Fig. 6: Injected Inverter current and its spectra with a) EMC-I-DPC b) EMC-I-VF-DPC at Pref=-2kW, Qref=0VAR
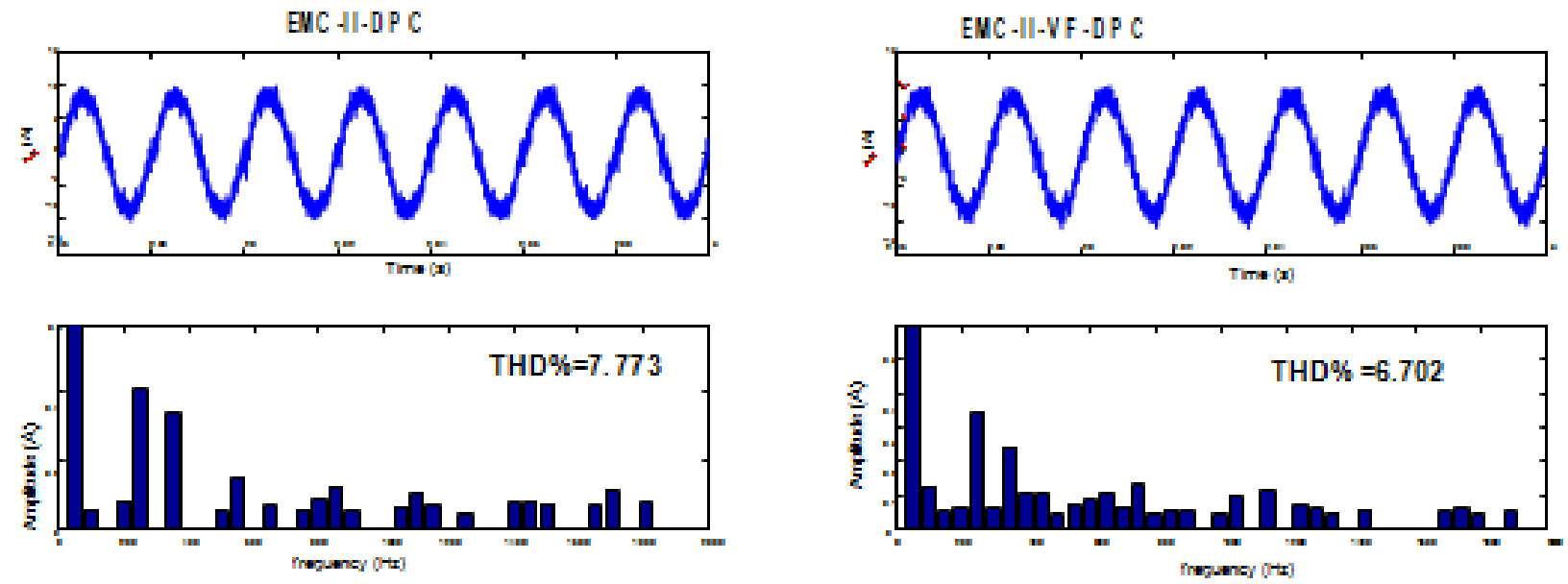

Fig. 7: Injected Inverter current and its spectra with a) EMC-II-DPC b) EMC-II-VF-DPC at Pref=-2kW, Qref=0 VAR
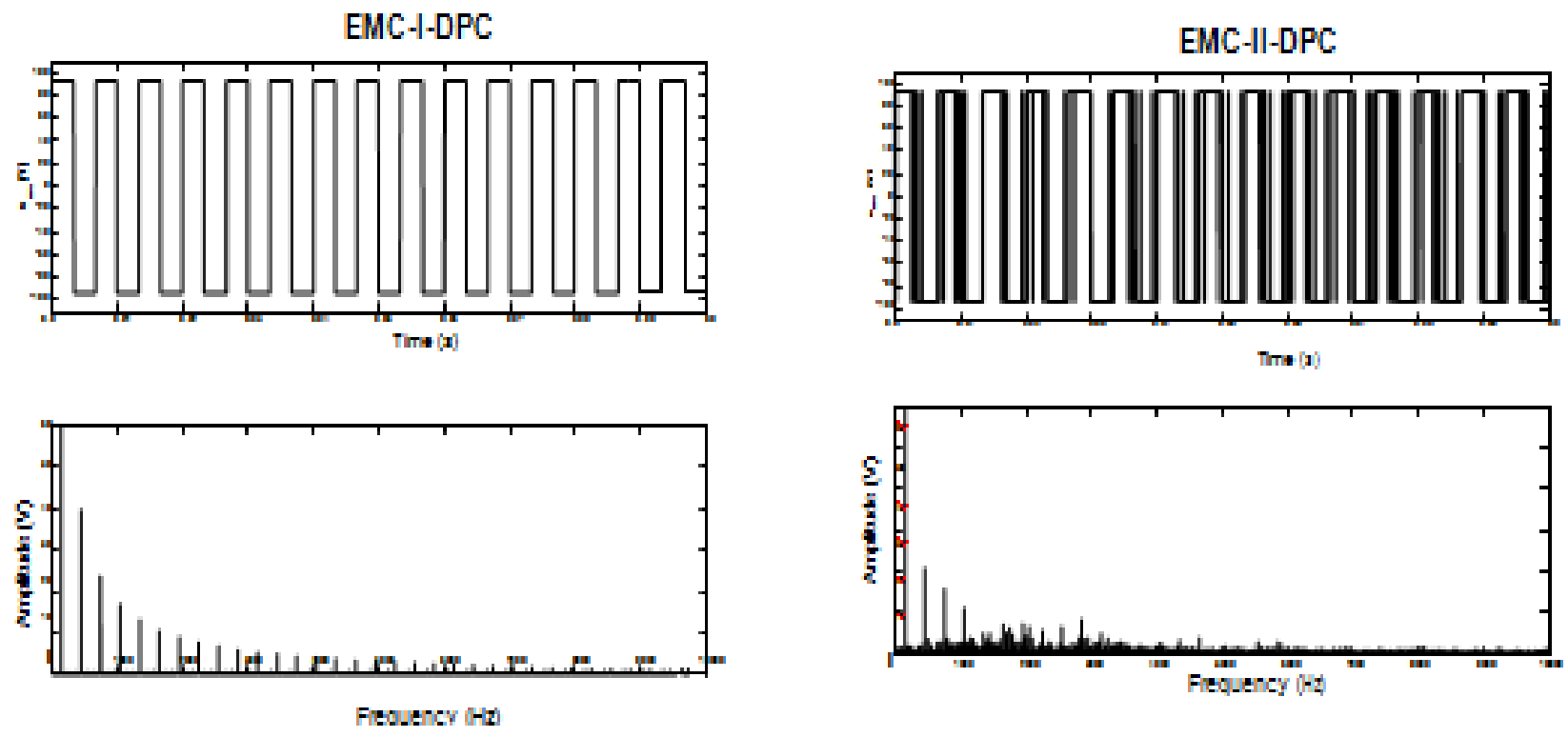

Fig. 8: CM emissions and its spectra with a) EMC-I-DPC a) EMC-II-DPC

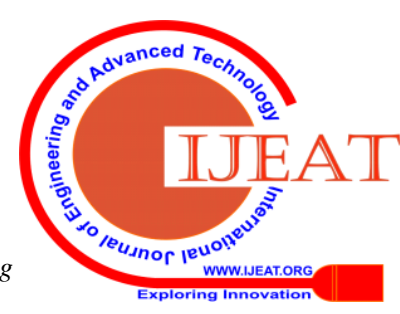


Electromagnetically Compatible and Virtual Flux DPC Control Techniques for 3-Phase Distributed Generation Fed by Active Rectifier

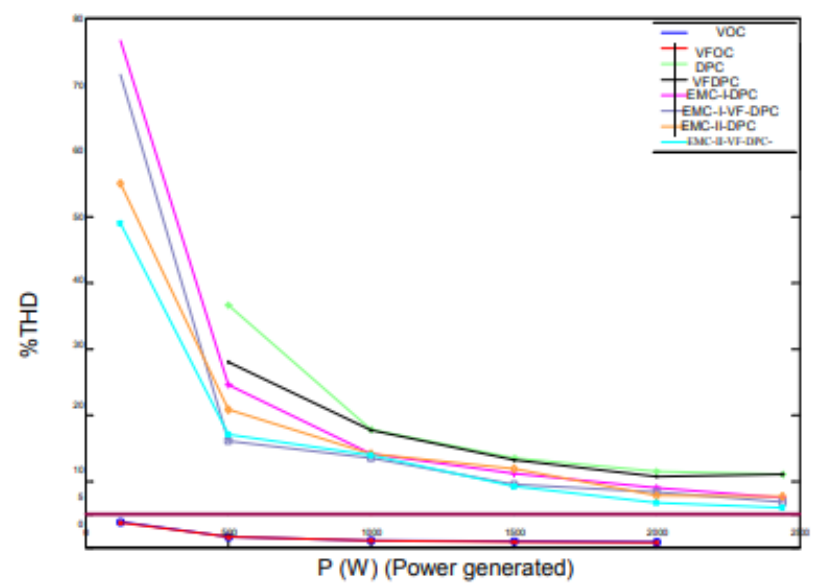

Fig. 9: Injected current \%THD vs. Power Generated

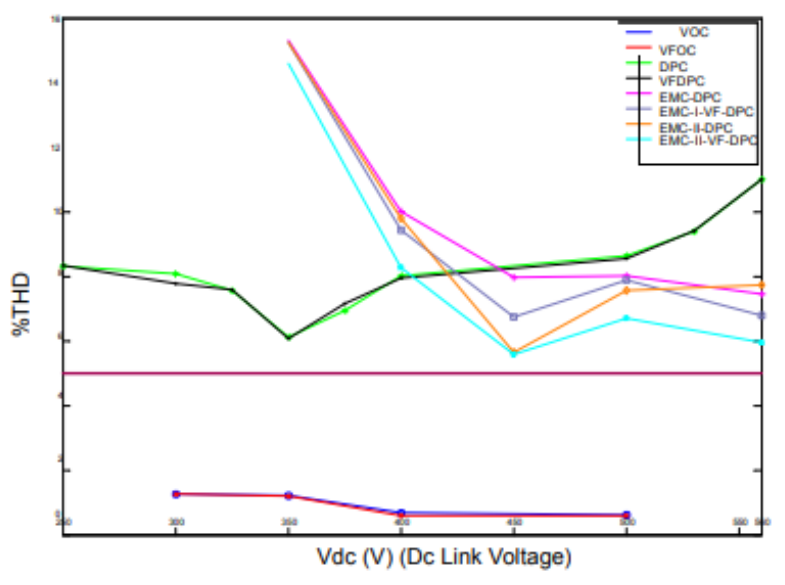

Fig. : 10 Injected current \% THD vs. DC link voltage (Vdc)

Table. VI: Common-Mode Voltage emissions comparisons control strategies

\begin{tabular}{|c|c|c|c|c|}
\hline $\begin{array}{c}\text { Control } \\
\text { Strategy }\end{array}$ & $\begin{array}{c}\text { Nature of CM } \\
\text { voltage Waveform }\end{array}$ & $\begin{array}{c}\text { Fundamental } \\
\text { Frequency at } \\
\text { which it occurs }\end{array}$ & $\begin{array}{c}\text { Harmonics Occurred at a } \\
\text { frequencies of }\end{array}$ & $\begin{array}{c}\text { Variation of } \\
\text { Harmonics with } \\
\text { frequency }\end{array}$ \\
\hline EMC-I-DPC & Square wave & $150 \mathrm{~Hz}$ & Only low frequency & $\begin{array}{c}\text { Decreasing with } \\
\text { frequency increase }\end{array}$ \\
\hline EMC-II-DPC & $\begin{array}{c}\text { Square wave with } \\
\text { internal spikes }\end{array}$ & $150 \mathrm{~Hz}$ & $\begin{array}{c}\text { Lower values at Low } \\
\text { frequency and } \\
\text { Higher values at High } \\
\text { frequency }\end{array}$ & $\begin{array}{c}\text { Increasing with } \\
\text { frequency increase }\end{array}$ \\
\hline
\end{tabular}

Table. VII: Comparison of VOC and Original DPC

\begin{tabular}{|c|c|}
\hline Control Strategy & \%THD \\
\hline VOC & 0.773 \\
\hline VF-OC & 0.725 \\
\hline DPC & 11.467 \\
\hline
\end{tabular}

Table. VIII: Comparison of Classical and Virtual Flux DPC

\begin{tabular}{|c|c|}
\hline Control Strategy & \%THD \\
\hline DPC & 11.467 \\
\hline VF-DPC & 10.685 \\
\hline
\end{tabular}

Table. IX: Comparison of Original and EMC-DPC

\begin{tabular}{|c|c|}
\hline Control Strategy & \%THD \\
\hline DPC & 11.467 \\
\hline EMC-I-DPC & 8.942 \\
\hline EMC-II-DPC & 7.773 \\
\hline
\end{tabular}

Table. X: Comparison of Virtual Flux and EMC-VFDPC

\begin{tabular}{|c|c|}
\hline Control Strategy & \%THD \\
\hline VF-DPC & 10.685 \\
\hline EMC-I-VF-DPC & 8.358 \\
\hline EMC-II-VF-DPC & 6.702 \\
\hline
\end{tabular}

Table. XI: Comparison of All DPC control techniques
\begin{tabular}{|c|c|}
\hline Control Strategy & \%THD \\
\hline VOC & 0.773 \\
\hline VF-OC & 0.725 \\
\hline DPC & 11.467 \\
\hline VF-DPC & 10.685 \\
\hline EMC-I-DPC & 8.942 \\
\hline EMC-I-VF-DPC & 8.358 \\
\hline EMC-II-DPC & 7.773 \\
\hline EMC-II-VF-DPC & 6.702 \\
\hline
\end{tabular}




\section{List of Symbols}

$\mathbf{u}_{\mathrm{s}} \mathrm{A}, \mathbf{u}_{\mathrm{sB}}, \mathbf{u}_{\mathrm{S}} \mathrm{C}$ : Phase Voltages of the inverter

is $_{\mathrm{A}}, \mathbf{i}_{\mathrm{SB}}$, isC : Phase Currents of the Inverter

$\mathbf{u}_{\mathrm{k}}: \mathrm{k}^{\mathrm{th}}$ Inverter voltage vector

$\mathbf{u}_{\overline{\bar{s}}} \mathrm{u}_{\mathrm{s}} \mathrm{s} \mathrm{j} \mathrm{u} \quad \dot{s}_{\mathrm{q}}$ Inverter voltages space vector in the grid voltage reference frame

$\mathbf{u g}^{\mathrm{u}}=$ ugd $+\mathrm{j}$ ugq : Inverter voltages space vector in the grid voltage reference frame

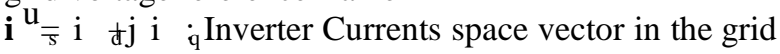

voltage reference frame

$\boldsymbol{\omega}=$ Pulsation of the Electric Grid

$\boldsymbol{P}, \boldsymbol{Q}$ : Active \& Reactive powers exchanged between Inverter and Electric Grid;

$\boldsymbol{L}, \boldsymbol{R}$ : Interconnection series inductance and its parasitic

Resistance

\section{FINAL CONCLUSIONS}

This paper proposed various Direct Power Control algorithms for grid connected distributed generation systems with non-conventional energy sources to control Active and Reactive power in generating mode. A detailed comparative result analysis made between existing and proposed techniques in the view point of harmonic content of injected currents into electric grid and \%Total harmonic distortion values at various levels of generated power. In results comparison mainly the ratio of Vdc and Vd magnitudes are considered and how this ratio effected the \%Total harmonic distortion of injected currents into the grid are studied.

Among the different DPC techniques, the poor performance is given by classical or original and the best performance is given by EMC-II-DPC. The other important point worth noting the actual and electromagnetically compatible direct power control algorithms gives a better and considerable performance when they are operated in virtual flux mode. In general, whatever the control strategy is used, the harmonic content of the injected current is so higher when the power generated is low.

If we look at the final results, with the consideration of different working conditions, one can easily understand that the best performance is given by the control algorithms in the sequence DPC followed by DPC-EMC-IDPC, EMC-II-DPC, VF-DPC, EMC-I-VF-DPC and EMCII-VF-DPC.

\section{REFERENCES}

1. M.P. Kazmierkowski, R. Krishnan and F. Blaabjerg,Control in Power Electronics, London, UK, 2002.

2. M. P. Kazmierkowski, "Current Control Techniques for Three-Phase Voltage-Source PWM Converters : A Survey", IEEE Transactions on Industrial Electronics, vol. 45, n. 5, October 1998, pp. 691703.

3. T. Noguchi, H. Tomini, S. Kondo, "Direct Power Control of PWM Converter Without Power-Source Voltage Sensor", IEEE Transactions on Industry Applications, Vol. 34, n. 3, May-June 1998, pp. 473-479.

4. M. Malinowski, Sensorless Control Strategies for Three - Phase PWM Rectifiers, PhD Thesis, University of Warsaw, Poland - 2001. M. Malinowski, M.P. Kazmierkowski, S. Hansen, F.

5. Blaabjerg, "Virtual-Flux-Based Direct Power Control of ThreePhase PWM Rectifiers", IEEE Transactions on Industry Applications, Vol. 37, n. 4,July-August 2001, pp. 1019-1027.

6. M. Malinowski, M.P. Kazmierkowski, M.Trzynadlowski, "A Comparative Study of Control Techniques for PWM Rectifiers in AC Adjustable Speed Drives", IEEE Transactions on Power Electronics, vol. 18, n. 6, November 2003, pp. 13901396.
7. M. Cirrincione, M. Pucci, G. Vitale, "Direct Power Control of ThreePhase VSIs for the Minimization of Common-Mode Emissions in Distributed Generation Systems", ISIE 2007 IEEE International Symposium on Industrial Electronics ISIE07, 4-7 June 2007 Vigo (Spain).

8. M. Cirrincione, M. Pucci, G. Vitale, "New Direct Power Control Strategies of Three-Phase VSIs for the Minimization of CommonMode Emissions in Distributed Generation Systems", The Fortysecond Annual Meeting of the IEEE Industry Applications Society (IAS 2007) New-Orleans USA Sept. 23 - 27,2007. 